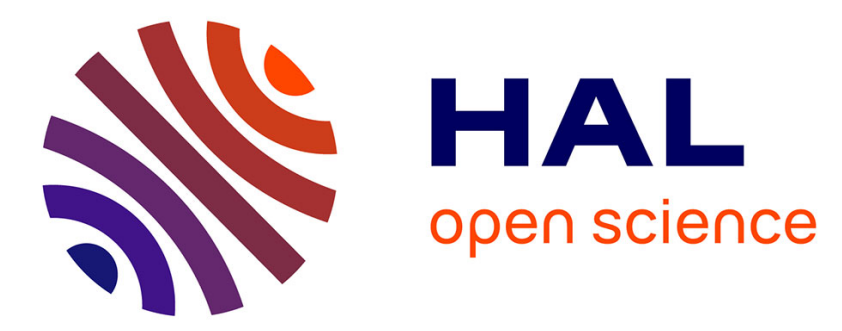

\title{
Dense water formation and cascading in the Gulf of Thermaikos (North Aegean), from observations and modelling
}

Claude Estournel, Vassilis Zervakis, Patrick Marsaleix, Anastasios

Papadopoulos, Francis Auclair, Leonidas Perivoliotis, Elina Tragou

\section{To cite this version:}

Claude Estournel, Vassilis Zervakis, Patrick Marsaleix, Anastasios Papadopoulos, Francis Auclair, et al.. Dense water formation and cascading in the Gulf of Thermaikos (North Aegean), from observations and modelling. Continental Shelf Research, 2005, 25 (19-20), pp.2366-2386. 10.1016/j.csr.2005.08.014 . hal-02110237

\section{HAL Id: hal-02110237 \\ https://hal.science/hal-02110237}

Submitted on 10 Aug 2021

HAL is a multi-disciplinary open access archive for the deposit and dissemination of scientific research documents, whether they are published or not. The documents may come from teaching and research institutions in France or abroad, or from public or private research centers.
L'archive ouverte pluridisciplinaire HAL, est destinée au dépôt et à la diffusion de documents scientifiques de niveau recherche, publiés ou non, émanant des établissements d'enseignement et de recherche français ou étrangers, des laboratoires publics ou privés.

\section{(c)(1)}

Distributed under a Creative Commons Attribution| 4.0 International License 


\title{
Dense water formation and cascading in the Gulf of Thermaikos (North Aegean), from observations and modelling
}

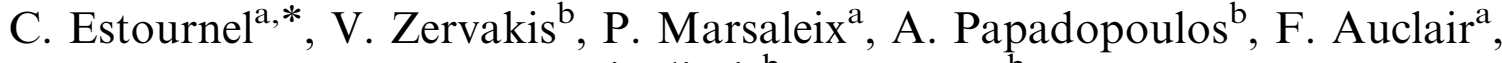 \\ L. Perivoliotis ${ }^{\mathrm{b}}$, E. Tragou ${ }^{\mathrm{b}}$

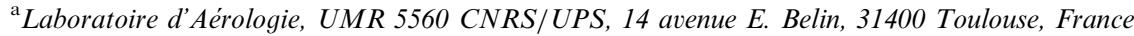 \\ ${ }^{\mathrm{b}}$ Institute of Oceanography, Hellenic Centre for Marine Research, P.O. Box 712, GR-19013 Anavyssos, Greece
}

\begin{abstract}
Observations of dense water formation on the shelf of the Gulf of Thermaikos (North Aegean) are presented, based mainly on continuous monitoring of temperature and currents, during the winter of 2001-2002, at an instrumented mooring and a CTD survey carried out in early February 2002. A 2.5-month realistic simulation, corresponding to the period of observation, was performed to investigate the processes of dense water formation and cascading. The simulation is first compared to the main characteristics of the dense water, time variation of bottom temperature and spatial distribution of the dense water on the shelf. Subsequently, the simulation is used (a) to show that the formation of dense water takes place within the semi-enclosed Thessaloniki Bay and (b) to explain the intermittence of cascading out of the bay in relation to wind variations. The pathways of the dense water through the shelf are investigated with an emphasis on the role of the bottom slope and friction in the Ekman layer. The export of dense water towards the open sea occurs primarily along the slope bounding the western coast.
\end{abstract}

Keywords: Dense water formation; Cascading; Numerical modelling; Thermaikos Gulf; Thessaloniki; Aegean Sea; Greece

\section{Introduction}

Thermaikos Gulf in the Northern Aegean Sea (Fig. 1), the Adriatic Sea and the Gulf of Lions are regions of the northern Mediterranean that are characterised by a large continental shelf, exposed to strong and frequent winds blowing from the continent. The North-South elongated shape of the Thermaikos Gulf (which is reminiscent of the Adriatic, but on a smaller scale) reduces the

\footnotetext{
*Corresponding author.

E-mail address: claude.estournel@aero.obs-mip.fr (C. Estournel).
}

influence of the deep basin circulation, especially in the confined northern part where the main rivers are located.

The hydrology of the Gulf of Thermaikos has been studied recently, on a seasonal basis, during four cruises organised in 1997-1998 within the framework of the Metro-Med project (Kontoyiannis et al., 2003). On seasonal time-scales, the variability of hydrology on the shelf is large and dominated by the signals of Black Sea water admixtures (evident in summer and autumn) and of discharge from the rivers (maximum in winter and spring). During the February 1998 cruise, the lowest temperatures $\left(<12^{\circ}\right)$ were observed in the bottom layers of the 


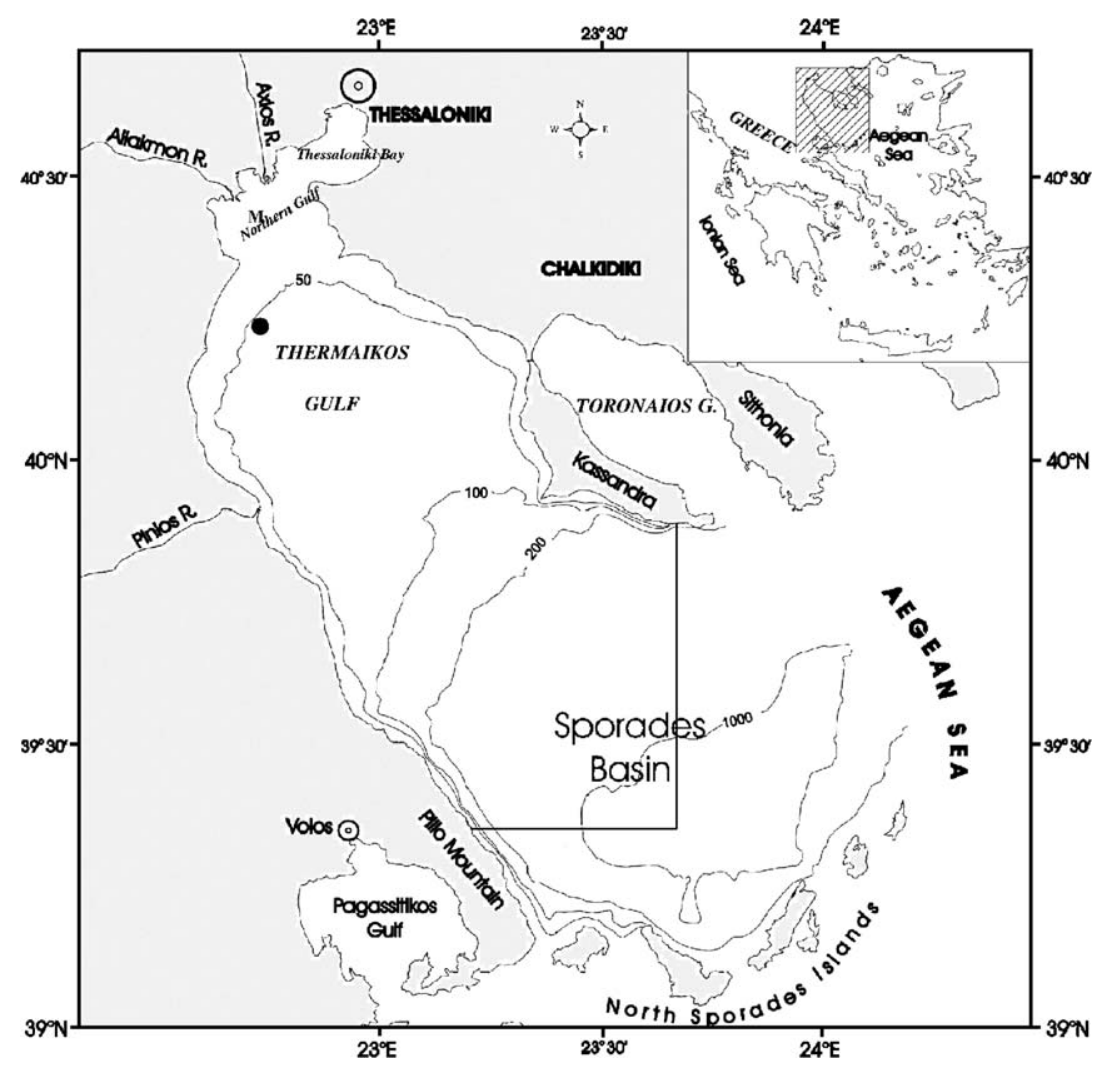

Fig. 1. Map of Thermaikos Gulf and the Sporades Basin. The insert presents the location of the Gulf in the Aegean Sea. Key: filled circle represents the position of the buoy; M the MTA mooring used in the study by Hyder et al. (2002). Solid lines indicate the East and South open boundaries of the TG model (for details, see text).

northern stations, i.e. in northern Thermaikos Gulf and in Thessaloniki Bay, which is a semi-enclosed area located at the northern extremity of the main gulf (Fig. 1). These cold water masses, formed by intense winter cooling, were observed also in May 1997, indicating a very slow bottom water exchange rate in the northernmost part of the gulf (Kontoyiannis et al., 2003). During the winter of 1994-1995, the PROFILE observational programme, based upon the deployment of long-term moored instrumentation and monthly CTD surveys, was undertaken in the northern Gulf and Thessaloniki Bay (Hyder et al., 2002). It was shown that dense water was formed between October and February, by cooling during northerly gales. Dense water was observed extending southward from Thessaloniki Bay, suggesting that its shallow waters were the place of formation. Thus, Thermaikos Gulf appears to be a region of dense water formation of the Mediterranean Sea, as is the case for the Gulf of Lions (Fieux, 1974) and the northern Adriatic Sea (Manca et al., 2002; Vilibic, 2003).
Various studies have focused upon the dense water formation in the open sea off the Gulf of Lions (e.g. MEDOC group, 1970; Madec et al., 1991), but the cascading of dense water at the shelf has also been observed and simulated at different periods (Person, 1974; Bethoux et al., 2002; DufauJulliand et al., 2004). These cold water masses formed on the shelf can be identified in the open sea at intermediate levels. Send et al. (1996) detected a cold anomaly at depths of between 1375 and $1500 \mathrm{~m}$, in 1994. Bethoux et al. (2002) showed that dense water originating from the shelf, in 1999, and observed at a depth of $1000 \mathrm{~m}$ in the Lacaze-Duthiers canyon (southwest of the Gulf of Lions) after a period of strong winds, was responsible for an anomaly covering the whole Algero-Provençal basin at $2000 \mathrm{~m}$. However, the importance of the process is very dependent upon the frequency and duration of the cold and dry wind events. According to the analysis of Bethoux et al. (2002), intense cascading of dense water formed on the shelf seems to occur every 8-11 years. Cascading 
of dense water is an efficient process for exporting particulate matter from the shelf to the deep sea. Although the duration of cascading in the winter of 1999 was short, it was noted that in the Gulf of Lions this means of exporting matter dominated other physical processes on an annual scale (Lapouyade and Durrieu de Madron, 2001).

In the case of the Gulf of Thermaikos, the presence of dense water has been observed, but the fate of such water is still not clear. Hyder et al. (2002) suggest from their observations that this dense water does not have sufficiently high salinity to act as a source of deep water for the Sporades Basin. In any case, the situation is very different from that in the Gulf of Lions. In the latter region, dense waters are formed mainly in the southwestern region (due to the more frequent occurrence of strong winds and, probably, to the great distance from the Rhone river, which reduces the density of coastal waters) where the shelf is narrow (about $25 \mathrm{~km}$ from the coast to the Lacaze-Duthiers canyon where the cascading was recorded). In the Gulf of Thermaikos, the northern region, which is probably the preferential area for the dense water formation, is about $100 \mathrm{~km}$ from the shelf break. The northern region is also the area where the main rivers are concentrated, which is a factor tending to inhibit dense water formation, but is favourable to the entrainment of sediment.

The main objectives of this paper are (a) to investigate dense water formation in Thermaikos Gulf, (b) to understand the preferential areas and the processes favouring, or inhibiting, this formation, and (c) to look at implications for cross-shelf exchanges and exportation, towards the deep sea. Our approach is based on the analysis of an instrumented mooring, a CTD survey and realistic numerical experiments. The first part of this paper presents the different types of observations available and the numerical model. The second part describes the meteorological conditions of the winter preceding the observations of dense water. In the third part, variation in the bottom and surface water temperatures and currents, monitored at a fixed buoy, provide a description of the chronology of the dense water formation; this assists in placing the synoptic period of observations within this temporal context. Finally, in the fourth section, the CTD survey will provide preliminary indication of the localisation and spatial extension of the dense water formation. In the following sections, the $3 \mathrm{D}$ numerical simulations will be first validated, and then used to examine the scientific questions listed above relating to the factors acting for or against dense water formation, subsequent cascading and the fate of the water mass formed.

\section{Material and methods}

\subsection{Field observations}

The bathymetry of Thermaikos Gulf, in the western part of the north Aegean Sea, is presented in Fig. 1. The bathymetry is characterised by an elongated shelf with a gentle slope (except along the coasts), limited in the South by a slope indented by two canyons about $15 \mathrm{~km}$ in width ending in the Sporades Basin, at a depth of about $1400 \mathrm{~m}$. Another characteristic is the presence of a small, shallow embayment, Thessaloniki Bay, at the northernmost part of the Gulf, near the city of Thessaloniki, the second largest city of Greece. The Thermaikos Gulf becomes narrower in its northern part, before connecting to the Thessaloniki Bay. This narrower part will be referred to as the northern Gulf, in all the text that follows.

Among the four major rivers discharging into the Gulf of Thermaikos, three (Axios, Loudias and Aliakmon) are located very near to each other in the northern Gulf; they have a total annual mean discharge of about $150 \mathrm{~m}^{3} \mathrm{~s}^{-1}$, whilst the Pinios river discharges, on the West coast, an annual mean rate of $50 \mathrm{~m}^{3} \mathrm{~s}^{-1}$ (Karageorgis and Anagnostou, 2001).

The mooring array used in Thermaikos Gulf, during the period September 2001-January 2003, was deployed at the position $40^{\circ} 14.96^{\prime} \mathrm{N}$ and $22^{\circ} 42.96^{\prime} \mathrm{E}$ in a water depth of $63 \mathrm{~m}$. The nearest coast was at a distance of about $10 \mathrm{~km}$, to the WNW of the mooring array (the nearest part of the eastern coast was about $20 \mathrm{~km}$ to the NE). The array consisted of an Oceanor Seawatch ${ }^{\circledR}$ buoy from HCMR's POSEIDON system monitoring network (Soukissian et al., 2002), a mooring equipped with two current meters set at $5 \mathrm{~m}$ above bottom (mab) and $7 \mathrm{mab}$, together with another mooring equipped with a sediment trap. The Seawatch ${ }^{\circledR}$ buoy was equipped with meteorological, sea-state and oceanographic sensors, along a CT string, for upper water column observations. The meteorological observations consisted of air temperature, atmospheric pressure and wind speed, gust and direction, taken at $3.5 \mathrm{~m}$ above the sea surface. The sea-state parameters included a full directional spectrum of the surface wave field, together with significant wave 
height, direction of propagation and period. The oceanographic observations included current speed and direction, temperature, salinity, chl- $\alpha$ concentration and dissolved oxygen, all at a $3 \mathrm{~m}$ depth below the sea surface. Attached to the Seawatch buoy was a string equipped with conductivitytemperature sensors, set at 5, 10, 20 and $30 \mathrm{~m}$ below the surface, and a pressure-temperature sensor at $35 \mathrm{~m}$ below the sea surface. All the parameters were sampled at 3-hourly intervals and transmitted in real time to the HCMR and to the world-wide web, through the POSEIDON system's webpage (www.poseidon.ncmr.gr). The two current meters on the neighbouring mooring (both of the Aanderaa RCM-9 type) were equipped with pressure gauges, as well as temperature, conductivity and turbidity sensors, and sampled at half-hourly intervals.

All the instruments underwent maintenance at regular intervals during the POSEIDON system's maintenance cruises. In particular, the "green" sensors of the POSEIDON buoy, and the conductivity cells of the CT string were calibrated regularly, following the in situ calibration procedures developed within the framework of the POSEIDON system's maintenance requirements (Zervakis et al., 2003).

Hydrographic data were collected during the February 2002 cruise of the R/V Aegaeo in the region, using an $\mathrm{SBE} 9 / 11+$ system sampling at $24 \mathrm{~Hz}$. An acoustic altimeter attached to the base of the CTD enabled the system to be lowered to a few tens of $\mathrm{cm}$ from the bottom (in calm weather conditions). The data underwent the standard quality control, filtering and $1 \mathrm{dbar}$ bin-averaging procedures, as described by the SBE manuals.

The observation period of the Gulf hydrography corresponded to the third INTERPOL cruise, which took place from 1 to 4 February 2002.

\subsection{The numerical model}

The 3D primitive equations, sigma coordinate coastal model SYMPHONIE, developed by the LA coastal group (http://poc.obs-mip.fr/) was used. A description of the model is given in Estournel et al. (2003). The free surface is calculated explicitly by decomposition of the model equations into internal and external modes, as proposed by Blumberg and Mellor (1987). A linear equation of state is used (Estournel et al., 1997). The advection scheme for temperature and salinity is a hybrid of centred and upstream schemes (Beckers, 1995). The vertical eddy viscosities and diffusivities are calculated according to the Gaspar et al. (1990) second-order closure scheme, with a prognostic equation for the turbulent kinetic energy and an algebraic formulation of the mixing and dissipation lengths.

The horizontal grid is orthogonal, with a grid spacing of $1 \mathrm{~km}$. The eastern open boundary intersects the extremity of the Kassandra Peninsula; thus, the Gulf of Toronaios, to the East of the peninsula, was not included in the model grid (Fig. 1). The horizontal resolution was selected at $1 \mathrm{~km}$, to represent not only the first deformation radius but also fine processes linked to the topography of the Thessaloniki Bay, whose characteristic scales are of the order of $10 \mathrm{~km}$. The use of generalised topography-following coordinate systems for coastal modelling is discussed in Pietrzak et al. (2002). These investigators showed that it is an efficient way to enhance vertical resolution in the surface or bottom boundary layers. We used such a system, with 25 vertical levels. The maximum water depth is $1260 \mathrm{~m}$. The minimum and maximum depths of the first level beneath the surface were 1.5 and $47 \mathrm{~cm}$, whilst the minimum number of levels in the first $10 \mathrm{~m}$ was 4 . Levels near the bottom were also contracted, to obtain a good representation of the bottom boundary layer: the first being at a height varying between $4.5 \mathrm{~cm}$ and $4 \mathrm{~m}$, above the bottom $(0.5 \mathrm{~m}$, at water depths of $100 \mathrm{~m})$.

The horizontal viscosity was taken as $5 \mathrm{~m}^{2} \mathrm{~s}^{-1}$ and the horizontal diffusivity zero. The bottom friction was quadratic, with the roughness length involved in the drag coefficient being $10^{-4} \mathrm{~m}$.

\subsubsection{Initial and boundary conditions}

Initial state and boundary conditions of the Thermaikos Gulf (TG) model were provided by the regional operational model of the Aegean Sea (AS), developed by the POSEIDON group. This is based on the Princeton Ocean Model (POM), with a curvilinear horizontal grid and a mesh of $0.05^{\circ}$ in the Aegean Sea. The sigma vertical coordinate uses 29 levels, 24 of them being equally spaced (every $4 \%$ of the water column), but the resolution increases in the upper layer ( 5 layers for the upper $4 \%$ of the water column). The model is nested in a model of the eastern Mediterranean, which provides hourly boundary conditions. The AS model produces a 3-day forecast, beginning every day at 12:00. The forecast procedure does not use any data assimilation. For the boundary conditions of the TG coastal model, we used the instantaneous 
outputs calculated $24 \mathrm{~h}$ after the initialisation of the AS model. This procedure provided a new field every day; these successive fields were interpolated linearly to obtain boundary conditions at each timestep of the TG coastal model. Before this step, the outputs of the regional AS model were made consistent with the TG coastal model characteristics (especially due to the bathymetry, which can be locally very different from the regional value), using the variational inverse method described by Auclair et al. (2000). This procedure aims at reducing the adjustment times, avoiding barotropic transients which could damage the simulation. The 3D fields (temperature, salinity and currents) were first interpolated using a Gaussian formulation on the horizontal and linear interpolation on the vertical. The sea surface elevation, the two components of transport and the depth-averaged density were adjusted then by constraining the mass conservation and a zero tendency of the momentum equations at the first time-step. The adjusted depth-averaged currents and density were substituted then, for their analogues, in the $3 \mathrm{D}$ variables. The boundary conditions were specified through a characteristic radiation condition (Oey and Chen, 1992). The initial state was obtained with the same procedure as the one used for the boundary conditions.

\subsubsection{Atmospheric forcing}

For the atmospheric forcing, the outputs from the POSEIDON weather forecasting system were used. The system is fully operational and is based on the Skiron/Eta model, a development of the 1997 version of the Eta/NCEP model (Kallos et al., 1997; Papadopoulos et al., 2002). To downscale the weather conditions, the model is executed twice with different configurations. The first simulation is performed with the coarser resolution model (COARSE), in order to provide detailed initial and boundary conditions for the second model with the higher resolution (FINE). The COARSE version of the model uses a horizontal grid increment of $0.24^{\circ}$, covering the Mediterranean Sea, South and Central Europe, and North Africa; the FINE, using a horizontal grid increment of $0.10^{\circ}$, covers the eastern Mediterranean region. The outputs of the National Center for Environmental Prediction (NCEP) Aviation (AVN) model, available from the NCEP ftp site, were used for the initial and the boundary conditions of the COARSE model. The POSEIDON weather forecasting system is run on a daily basis, starting at 12 UTC, and provides $72-h$ forecasts. For this study, the first $24-\mathrm{h}$ model outputs of each daily simulation of the FINE model (in fact, from 3 to $27 \mathrm{~h}$ into forecast, in order to avoid "spin-up" of the model) were used. The use of a high-resolution atmospheric model is of primary importance for such a study, to take into account the effect of orography constraining the wind field (the 2000-m-high Olympus Mountain is about $10 \mathrm{~km}$ from the west shoreline); also, the landsea discontinuity, which produces land-sea breeze effects that modulate the wind field. The parameters are the radiative solar and long-wave fluxes, the air temperature and humidity at $2 \mathrm{~m}$ and the wind at $10 \mathrm{~m}$. The wind stress, together with the latent and sensible heat fluxes, were calculated from the air parameters and from the sea surface temperature given by the TG coastal model at its uppermost level, using the iterative bulk formulae based on the Monin-Obukhov similarity theory (see, for example, Geernaert, 1990). The various coefficients used in the stratification universal functions and the different expressions for the drag coefficient, Stanton and Dalton numbers in neutral conditions, may be found in Large and Pond (1982).

\subsubsection{River input}

The freshwater discharge of the main rivers (Axios, Pinios and Aliakmon) was introduced as a lateral boundary condition. As discussed later, the rivers' discharge was not measured during the period which is studied here. Different simulations were performed, with different hypotheses on these discharges. As in Estournel et al. (2003), the outflow was prescribed as a transport deduced from the geometrical characteristics (width and depth) of the cell. The baroclinic velocity was prescribed using a simple logarithmic profile and salinity was set to zero. Seasonal variations were imposed on the freshwater temperature.

\section{Description of the meteorological conditions}

Fig. 2 presents the time variation of air temperature and wind measured at the buoy (at $3.5 \mathrm{~m}$ ), together with the values produced by the meteorological model at the nearest grid point and at $10 \mathrm{~m}$ (a correction described below was applied to the wind speed); this was then used to compute the momentum and heat fluxes at the surface. The days are numbered from 1 January 2001, so as to be continuous over the winter 2001-2002. As far as the observations are concerned, it can be seen that the 

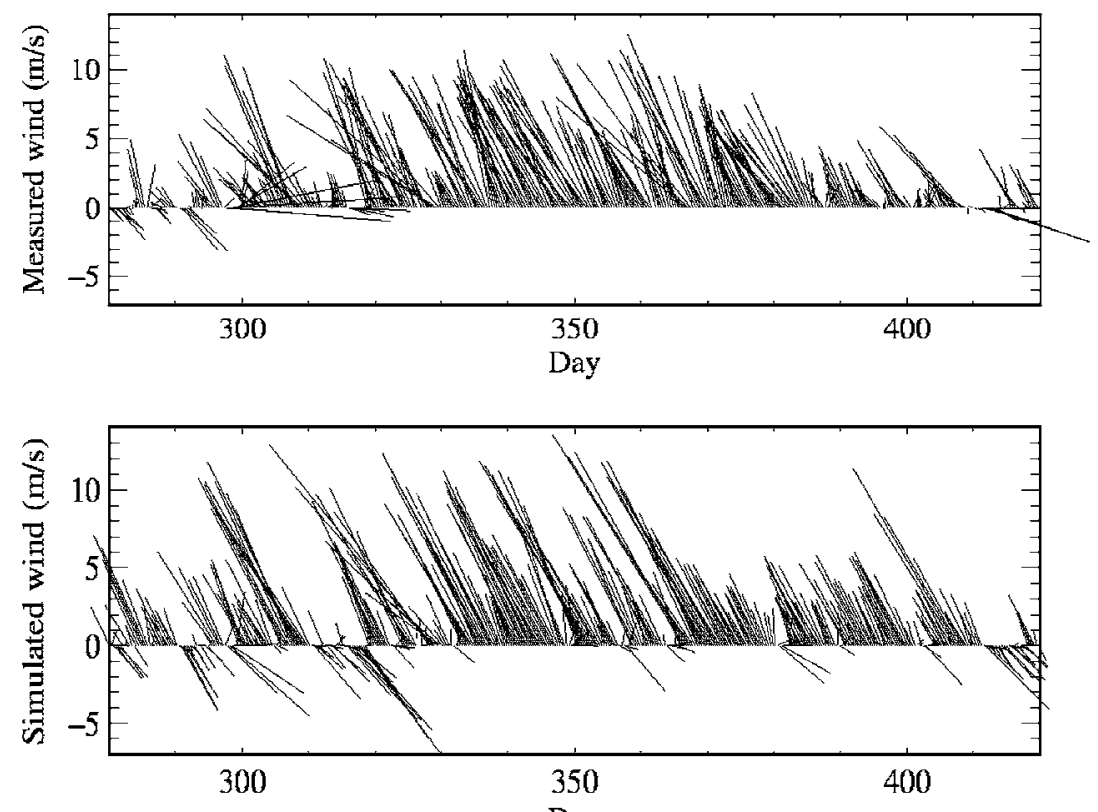

(a)

Day

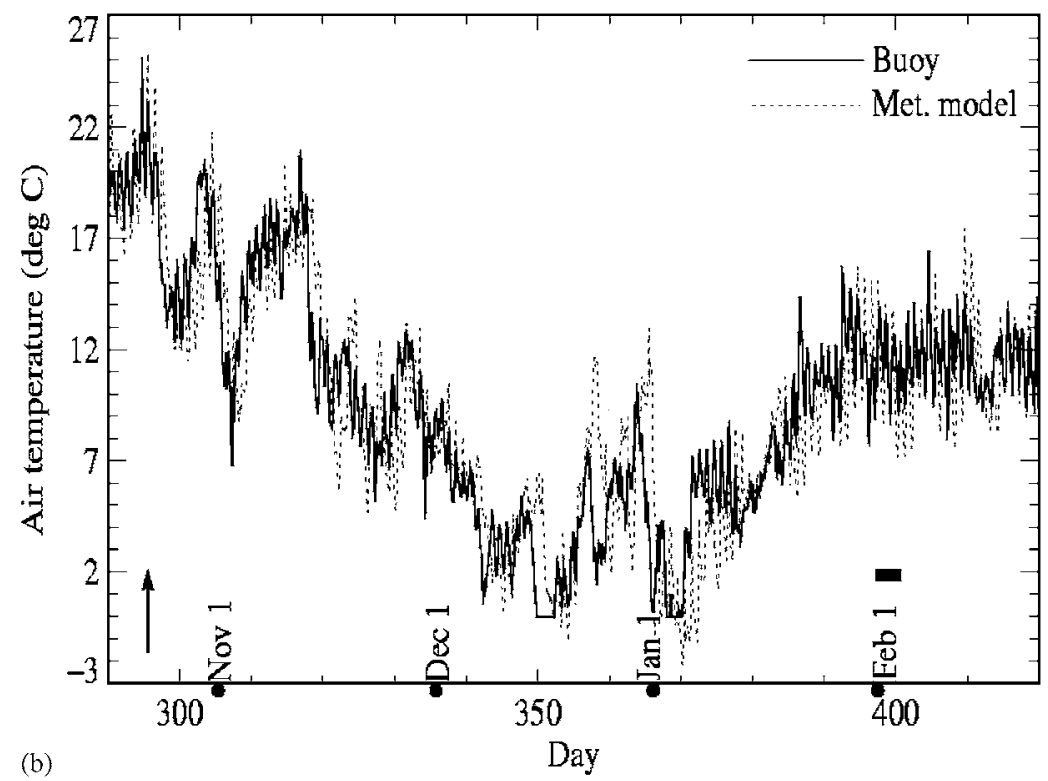

Fig. 2. Wind vectors (a) and air temperature (b) measured at the buoy and computed by the meteorological model. Note that the wind speed from the model was increased following the regression presented in Section 3. Days are numbered from 1 January 2001. The vertical arrow indicates the beginning of the simulation and the horizontal bar (around day 400) the period of the third INTERPOL cruise. Temperatures lower than $0^{\circ} \mathrm{C}$ were not recorded.

wind direction (northwest, i.e. along the main direction of the gulf) was nearly constant throughout the whole of the period. For about 2 months, the wind speed was well established, with a mean value of about $8 \mathrm{~m} \mathrm{~s}^{-1}$ and peaks at $15 \mathrm{~m} \mathrm{~s}^{-1}$ (smoothing was applied for clarity of the figure).
At the beginning of this period of sustained wind (days 310-320), the air temperature fell and remained at a particularly low level around the end of the year. These low values of air temperature, coupled with strong winds, produced high heat losses for the sea and constituted favourable 
conditions for the formation of dense water. The INTERPOL cruise took place about 20 days after the wind decay. During the cruise, the air temperature remained at typical mild early spring values.

In order to verify the model's potential in forecasting the wind speed, a statistical comparison between the estimated values and the observations from the buoy and the surface meteorological station at Thessaloniki airport was performed. The sample consisted of all the available pairs of model values and corresponding observations, in the first $24 \mathrm{~h}$ of each daily simulation and for the period from 1 June 2001 to 31 March 2002. In order to investigate the model's performance in greater detail, the sample was divided into 3 subsets according to the observations. Table 1 shows the results of the verification.

Based on this analysis, an empirical regression was applied to the wind speed, of the form

$$
\left.V_{\mathrm{a}}=V_{\mathrm{b}} \exp \frac{1}{1.5 V_{\mathrm{b}}^{0.3}}\right) \text { for } V_{\mathrm{a}} \geqslant 0.1 \mathrm{~m} \mathrm{~s}^{-1} \text {, }
$$

where $V_{\mathrm{b}}$ is the wind speed from the forecasting model and $V_{\mathrm{a}}$ is the result of the regression.

Performing the same verification after this adjustment showed a satisfactory improvement in the model's capabilities. The results of the statistical evaluation are summarised in Table 2.

The wind direction and the other parameters of the meteorological model were not modified. The values obtained by this regression are presented in Fig. 2. During the period studied (we will see later that the coastal simulation began on 22 October, day 295), the main characteristics of the wind history recorded at the buoy were well reproduced

Table 1

Statistical comparison of wind speed from the forecasting system, with observations from the buoy and from Thessaloniki airport

\begin{tabular}{|c|c|c|c|c|c|c|}
\hline & \multicolumn{3}{|l|}{ Buoy } & \multicolumn{3}{|c|}{ Thessaloniki } \\
\hline & RMSE & MAE & BIAS & RMSE & MAE & BIAS \\
\hline$V_{\mathrm{obs}} \geqslant 1 \mathrm{~m} \mathrm{~s}^{-1}$ & 3.31 & 2.59 & -2.14 & 2.65 & 2.08 & -1.82 \\
\hline$V_{\mathrm{obs}}<5 \mathrm{~m} \mathrm{~s}^{-1}$ & 1.77 & 1.44 & -0.65 & 1.68 & 1.42 & -1.10 \\
\hline $5 \leqslant V_{\mathrm{obs}}<10 \mathrm{~ms}^{-1}$ & 3.74 & 3.24 & -3.08 & 3.21 & 2.78 & -2.61 \\
\hline$V_{\mathrm{obs}} \geqslant 10 \mathrm{~m} \mathrm{~s}^{-1}$ & 5.37 & 4.76 & -4.70 & 6.01 & 5.34 & -5.20 \\
\hline
\end{tabular}

RMSE, root mean square error; MAE, mean absolute error; BIAS, mean error; $V_{\text {obs }}$, observed wind speed (all values in $\mathrm{m} \mathrm{s}^{-1}$ ).
Table 2

As Table 1, after adjustment of the wind from the forecasting system

\begin{tabular}{|c|c|c|c|c|c|c|}
\hline & \multicolumn{3}{|l|}{ Buoy } & \multicolumn{3}{|c|}{ Thessaloniki } \\
\hline & RMSE & MAE & BIAS & RMSE & MAE & BIAS \\
\hline$V_{\mathrm{obs}} \geqslant 1 \mathrm{~m} \mathrm{~s}^{-1}$ & 2.87 & 2.26 & 0.04 & 2.20 & 1.68 & -0.16 \\
\hline$V_{\mathrm{obs}}<5 \mathrm{~m} \mathrm{~s}^{-1}$ & 2.42 & 1.91 & 0.96 & 1.76 & 1.39 & 0.23 \\
\hline $5 \leqslant \mathrm{~V}_{\mathrm{obs}}<10 \mathrm{~ms}^{-1}$ & 3.05 & 2.50 & -0.71 & 2.48 & 1.96 & -0.57 \\
\hline$V_{\mathrm{obs}} \geqslant 10 \mathrm{~m} \mathrm{~s}^{-1}$ & 3.63 & 2.83 & -1.12 & 4.18 & 3.18 & -2.20 \\
\hline
\end{tabular}

by the model especially during the strong wind events. The agreement was not so good during the relatively calm period following the storm, between days 372 and 385, where the model underestimated the moderate wind observed. The variation of air temperature was also generally well reproduced by the meteorological model. Concerning the wind at the scale of the gulf, the meteorological model shows that it generally increases from North to South, with a mean factor of 1.5 between the western coast of the Sporades basin (latitude: $39.4^{\circ} \mathrm{N}$ ) and the North of Thermaikos Gulf.

\section{Description of the hydrography}

\subsection{Time series}

\subsubsection{Surface and bottom temperatures}

Fig. 3 presents the variation in temperature recorded at the buoy, in the surface and bottom waters. Starting from the second half of October, the surface water cools rapidly, resulting in a progressive destratification; this ends in midNovember, when the water column appears homogeneous. During the following 25 days, both the levels cool synchronously. At this time (around day 345, 11 December), the strong wind becomes much more persistent, with the air temperature being not far from $0{ }^{\circ} \mathrm{C}$ (Fig. 2); the bottom water becomes colder than the surface water over most of the time. However, high-frequency fluctuations of bottom temperature are markedly stronger than the surface fluctuations, inducing a succession of stratified and quasi-mixed conditions (as far as these two points can be considered indicative of the stratification). After a short event, characterised by especially cold bottom water centred on day 379 (January 14), bottom temperature, although subject to large 


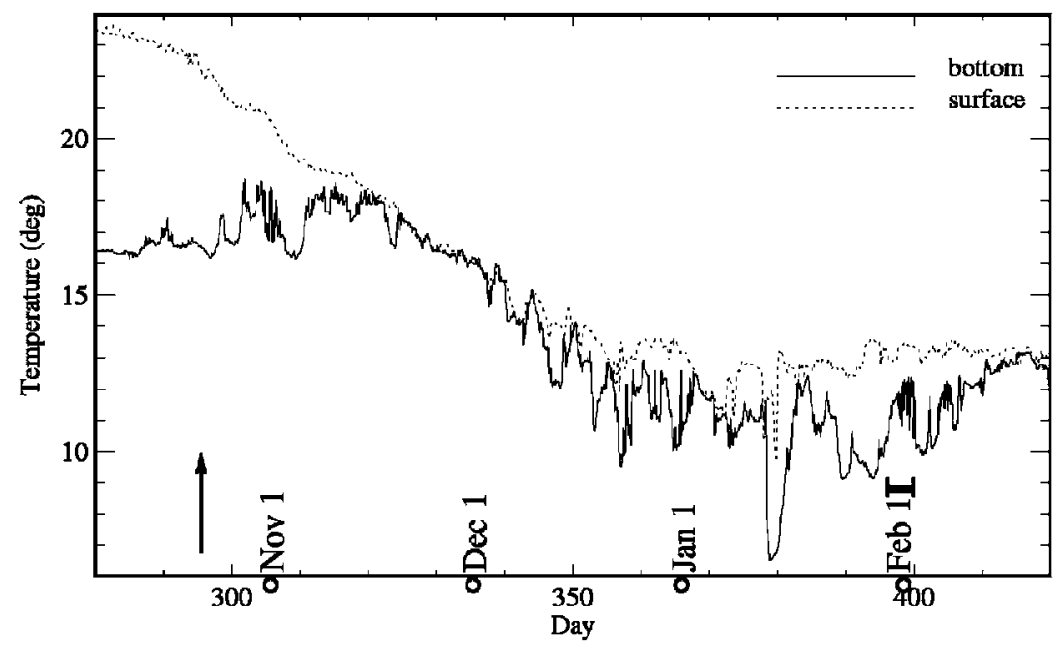

Fig. 3. Water temperature measured at $3 \mathrm{~m}$ below the surface (dotted line) and at $5 \mathrm{~m}$ above the bottom (solid line), at the buoy. The vertical arrow indicates the beginning of the simulation and the horizontal bar (around day 400) the period of the third INTERPOL cruise.
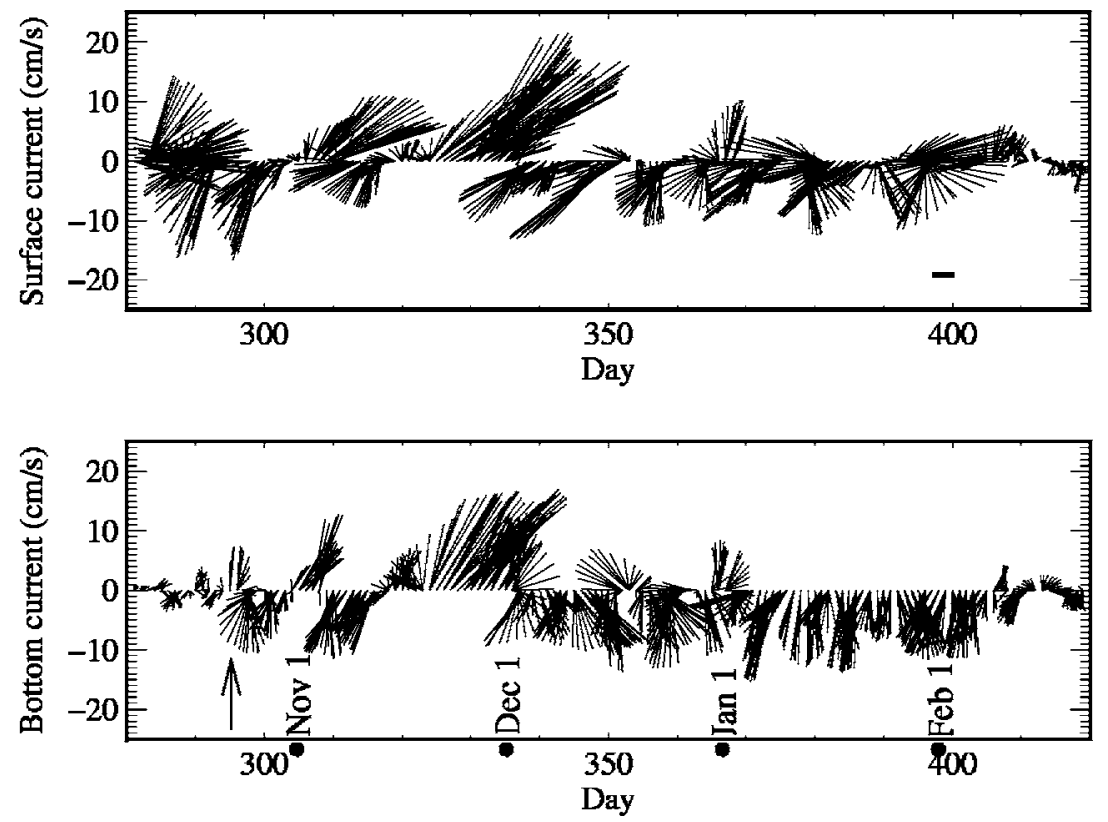

Fig. 4. Time series of currents measured at $3 \mathrm{~m}$ below the surface and at $5 \mathrm{~m}$ above the bottom, at the buoy.

variations, remains on average significantly colder than the surface water; this is until an increase of temperature allows mixed conditions to be reached again, on day 415 (19 February).

\subsubsection{Surface and bottom currents}

The variation of surface and bottom low-pass filtered currents, recorded at the buoy, is presented in Fig. 4. Before day 300 (around the end of
October), bottom and surface currents are decoupled, as is generally the case in stratified conditions: surface water can be accelerated by the wind, whilst bottom currents remain at a low level. Both currents are characterised by a few days of high northward velocities, around day 325. On day 335 , both currents start to flow towards the South. In the following weeks, whilst the surface current exhibits frequent changes of direction, the bottom 
current remains southward, until day 400 (progressive vector plots will be presented later). We should point out that the temperature at both depths is similar (signifying vertical homogeneity) until day 335 , when the temperature at the bottom current meter drops sharply; it then remains lower than the surface temperature (except for short periods) until day 415. Thus, the southward flow near the seabed carries water colder than the rest of the water column, towards the South. After day 400, both currents sharply decrease to a few $\mathrm{cm} \mathrm{s}^{-1}$ (with a delay of a few days for the bottom current), which is coincident with the beginning of the bottom water heating.

These temperature and current time series indicate that after a period characterised by a progressive mixing of the water column under the action of several strong wind events in autumn, dense water is formed in relation with large heat losses produced by strong and cold North winds. Cold bottom water at the buoy, associated with southward bottom current, was recorded over more than 60 days (except for some intermittences); about 25 days of this followed the breakdown of the strong winds. This pattern indicates that the dense water, formed in the North, cascaded in a layer of at least $5 \mathrm{~m}$ in thickness. The dense water cascade probably stopped around day 400 at the buoy as can be inferred both from a progressive heating near the bottom (probably due to the advection of marine water) and from the sharp decrease in current. This chronology indicates that the CTD survey carried out around 1 February (day 397) probably provides a reasonable picture of the spatial distribution on the shelf, of the cold water masses formed during the preceding months.

\subsection{The February CTD survey}

\subsubsection{Surface and near-bottom fields}

The 48 CTD profiles were measured on the shelf of the Gulf of Thermaikos, between 1 and 4 February (days 397-400). The surface and bottom temperature and salinity fields are presented in Fig. 5. A good correlation between salinity and temperature appears in the surface fields. The influence of rivers is clear in the North of the gulf and, to a lesser extent, along the western coast. Near the bottom, the temperature/salinity correlation still exists, with cold and less salty water in the North and in a band parallel to the West coast. The contrast in temperature (locally $>4{ }^{\circ} \mathrm{C}$ ) between these water masses, with the marine waters located over the eastern part of the gulf, is much more important than the contrast of salinity $(0.5 \mathrm{psu})$ as far as the effect on density is concerned. The marked differences in temperature, which exist between surface and bottom waters in these cold regions, are in agreement with the time series discussed above.

\subsubsection{Vertical sections}

Fig. 6 presents a zonal vertical section of temperature, salinity and density obtained from the $6 \mathrm{CTD}$ profiles located at approximately $40.15^{\circ} \mathrm{N}$ (see Fig. 1). This figure shows clearly, at the surface, the narrow river plume flowing along the West coast; at the bottom, the layer of dense water, about $10 \mathrm{~m}$ thick, appears well separated from the upper layer by a marked density interface. The different CTD profiles located in the dense water area exhibit nearly the same characteristics: relatively well-mixed profiles, inside a $10 \mathrm{~m}$ thick dense layer. The bottom density in the dense water area varies between $1029.8 \mathrm{~kg} \mathrm{~m}^{-3}$ to the North, and $1029.5 \mathrm{~kg} \mathrm{~m}^{-3}$ to the South; this is clearly higher than the density of the "marine" eastern waters $\left(1029.15 \mathrm{~kg} \mathrm{~m}^{-3}\right)$ and as such can explain the cascading.

\subsection{Summary of hydrography}

It is clear that a significant fraction of the gulf is covered by dense bottom water, which has its origin in a region influenced by rivers. The presence of both the coldest waters and the main rivers in the North implies that these dense waters have been formed in the North of the gulf, or in the Thessaloniki Bay. All the CTD profiles of the northern region (excluding the Thessaloniki Bay) present a well-formed dense bottom layer, with a maximum density in the central part. This pattern could indicate either an old dense water lens formed locally, which spread and collapsed under the effect of gravity and diffusion, or the cascading of dense water formed in the Thessaloniki Bay. We will see that the simulation confirms this second hypothesis.

It is interesting to compare this situation to other winters, to obtain an idea of the frequency of such events. The meteorological parameters measured every $3 \mathrm{~h}$ at the Thessaloniki meteorological station, during 12 winters between 1992 and 2004, were analysed to examine cold wind events. Thresholds were applied to the wind velocity (values greater 

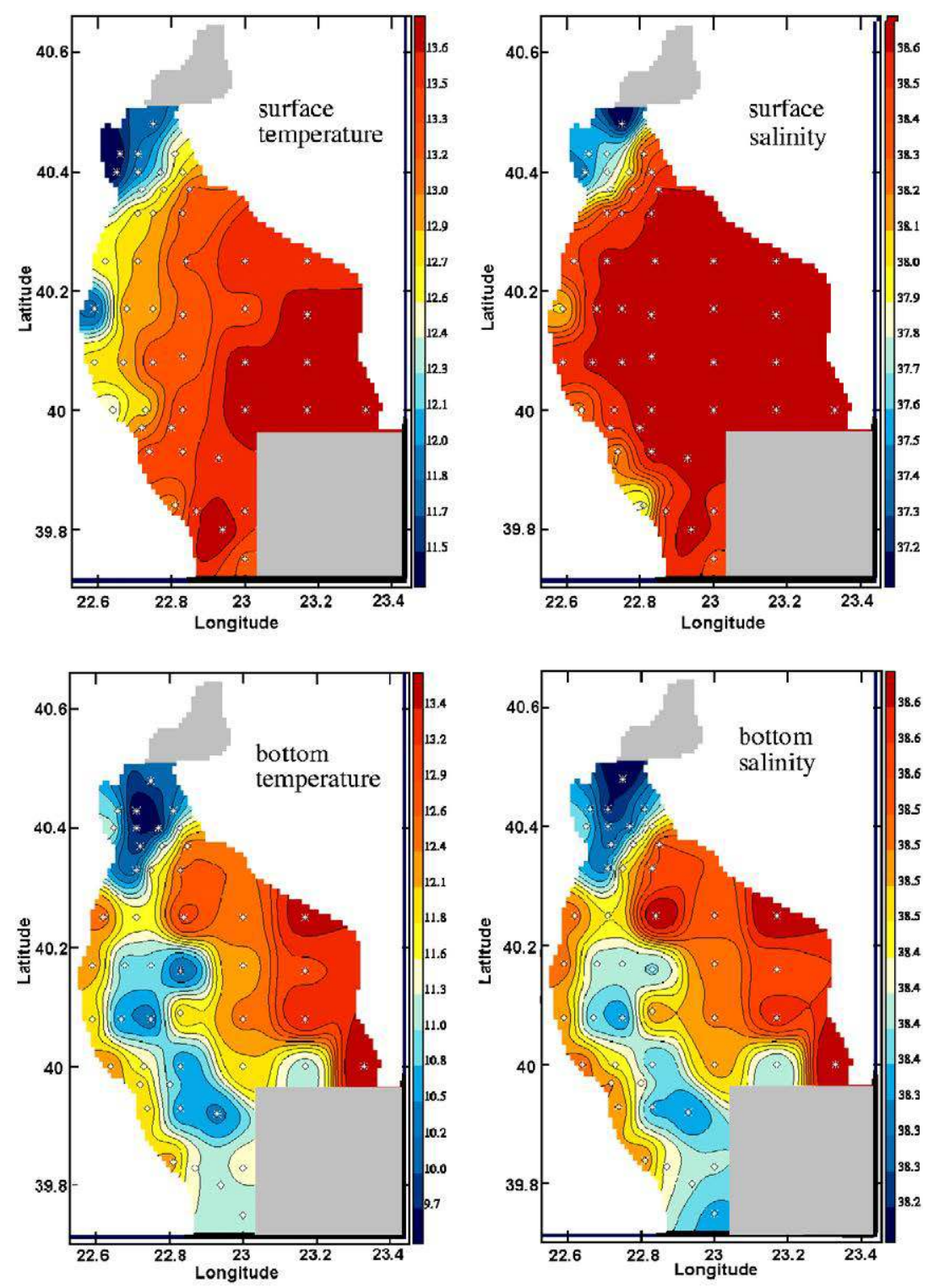

Fig. 5. Surface (upper panels) and bottom (lower panels) temperature $\left({ }^{\circ} \mathrm{C}\right.$ ) and salinity fields (psu), deduced from the CTD profiles between 1 and 4 February (days 397 and 400). The positions of the CTD measurements are indicated. Areas without data have been coloured in grey.

than $7 \mathrm{~m} \mathrm{~s}^{-1}$ ) and air temperature (values lower than $\left.2{ }^{\circ} \mathrm{C}\right)$. The number of 3 -h observations beyond the thresholds were counted, for each year (a sensitivity analysis was performed on the values of the thresholds, to check that the results were not too dependent on them). For the 12 winters, the annual average of these observations was 19. Two years were far above this average, the winter of 2003-2004 with 53 observations and the winter of 2001-2002, corresponding to the period described in this paper, with 40 observations. The number of observations was lower that 12 , for 6 years; for the other 4 years, the number of events was between 19 and 30 . Amongst these latter 4 moderate years, the winter of 1994-1995, with 19 events concentrated over 4 successive days, has been described by Hyder et al. (2002). Temperature and salinity were recorded at a mooring located in the northern gulf $\left(40.43^{\circ} \mathrm{N}\right)$, located about $20 \mathrm{~km}$ North of our buoy. Similarities exist between this temperature series and the one 

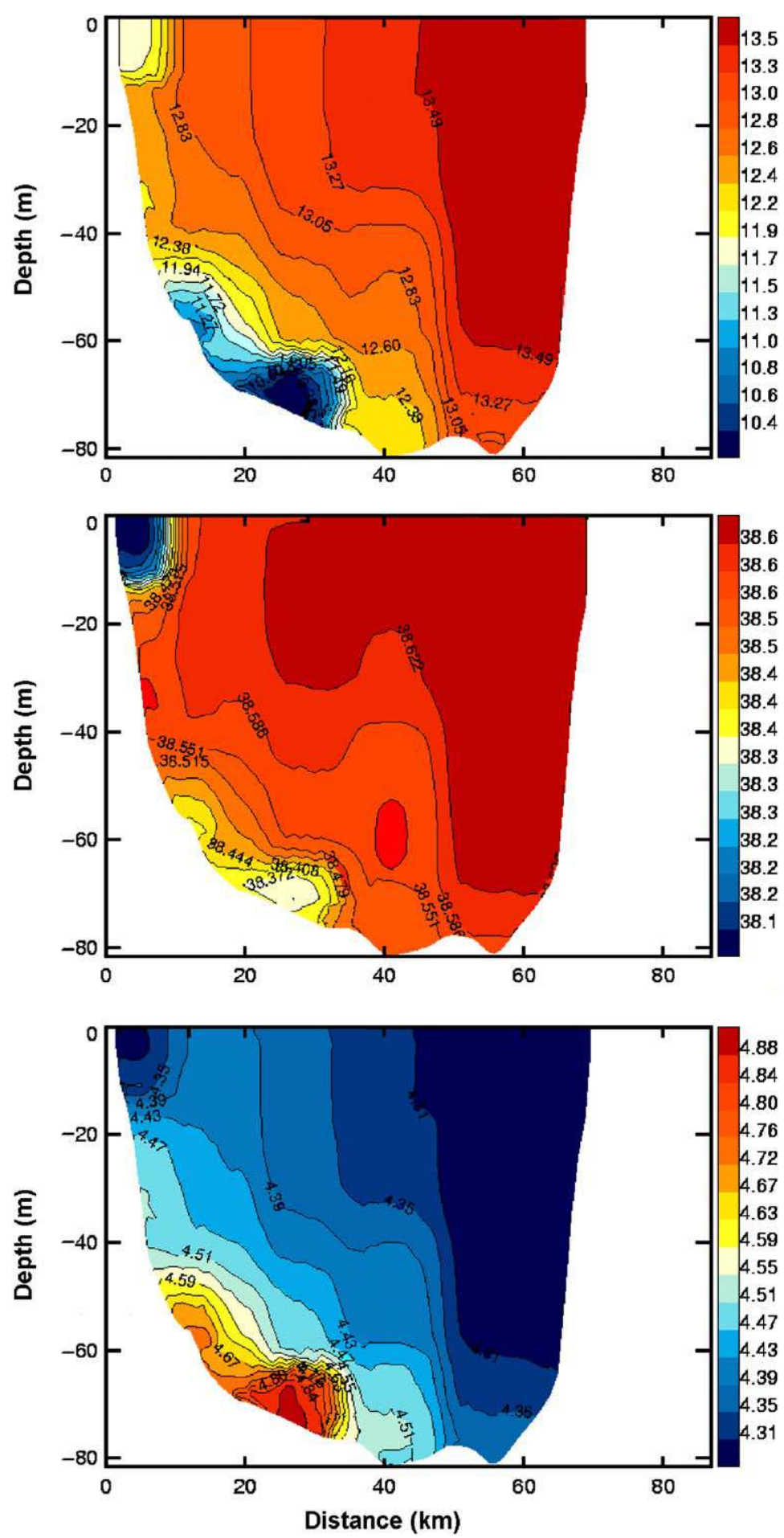

Fig. 6. Vertical zonal sections of temperature (top panel, in ${ }^{\circ} \mathrm{C}$ ), salinity (middle panel, in psu) and density anomaly (bottom panel, in $\mathrm{kg} \mathrm{m}^{-3}$, reference value: 1024.8) deduced from the CTD profiles corresponding to a latitude of $40.15^{\circ} \mathrm{N}$.

presented in the present paper: as for the data shown here, vertical mixing occurred around day 320 , followed by cooling at both levels until a strong event, characterised by a sharp decrease of temperature down to $8{ }^{\circ} \mathrm{C}$. However, the period characterised by the presence of cold water was 
shorter than during the winter 2001-2002, especially if we consider that the mooring used by Hyder et al. (2002) was closer to the formation area than ours; as such, it could have been expected to capture more of the cascading events. We can conclude then that dense water formation is not exceptional in this region, occurring probably each time that a cold North wind blows for a few days. However, processes of the intensity and duration noted during the observation period are probably rarer, i.e. about two occurrences within the last 12 years.

\section{Description of dense water formation and cascading from the simulation}

The simulation was initialised on 22 October (day 295) and run until the beginning of February (the period of the cruise). The beginning of the run is clearly representative of stratified conditions, with a sea surface temperature of $23^{\circ} \mathrm{C}$ measured at the buoy (Fig. 3) and air temperature typical of "late summer conditions". No direct information is available on the rivers' discharge. However, different elements support the concept of reduced riverine discharge. Firstly, a study of monthly precipitation in Thermaikos Gulf and the adjacent catchment area (Tragou et al., 2004) showed notably lower values than the climatological mean from October 2001 to February 2002 (with the exception of December). Secondly, the surface salinity measured by the CTD was lower than 37 (36.94) at only one station located $3 \mathrm{~km}$ from the Axios river mouth (Fig. 5). It was decided then to carry out two simulations: one with climatological values of the river discharge and the other with a zero discharge, giving two extreme states between which the experimental conditions probably lay. The objective was to see if the observations were in reasonable agreement with one or both simulations; likewise, to study the sensitivity of dense water formation to freshwater discharge. More precisely, we wanted to know if the dense water formation was related only to the meteorological conditions (strong and cold winds in winter), or if the low river discharges during autumn 2001 also played a significant role. The mean discharge rates chosen for the three main rivers Axios, Pinios and Aliakmon were 100, 20 and $20 \mathrm{~m}^{3} \mathrm{~s}^{-1}$ for autumn and 200, 170 and $70 \mathrm{~m}^{3} \mathrm{~s}^{-1}$ for winter, based upon Kontoyiannis et al. (2003) and Karageorgis and Anagnostou (2003). The riverine water temperature was set to decrease from 17 to $8{ }^{\circ} \mathrm{C}$ during the simulation period. Sensitivity to the freshwater temperature was also investigated, using a temperature minimum of $2{ }^{\circ} \mathrm{C}$ instead of $8{ }^{\circ} \mathrm{C}$.

In the following, we shall focus upon the validation of the simulation, by comparison with the observations. Fig. 7 presents the variation of bottom temperature, at the grid point corresponding to the position of the buoy for both the simulations. The mean variation of simulated

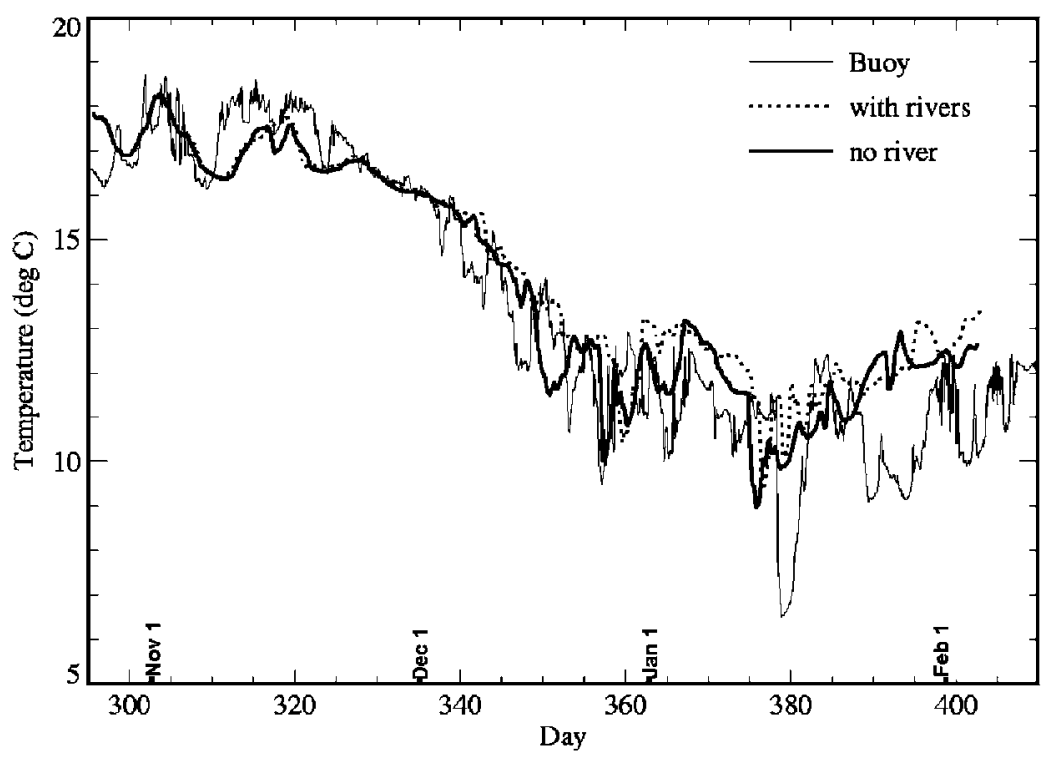

Fig. 7. Water temperature at $5 \mathrm{~m}$ above the bottom. Key: Thin solid line - measured at the buoy; dashed line - simulation with river discharge; thick solid line - simulation without river discharge. The horizontal bar below the $x$-axis indicates the period of the cruise. 

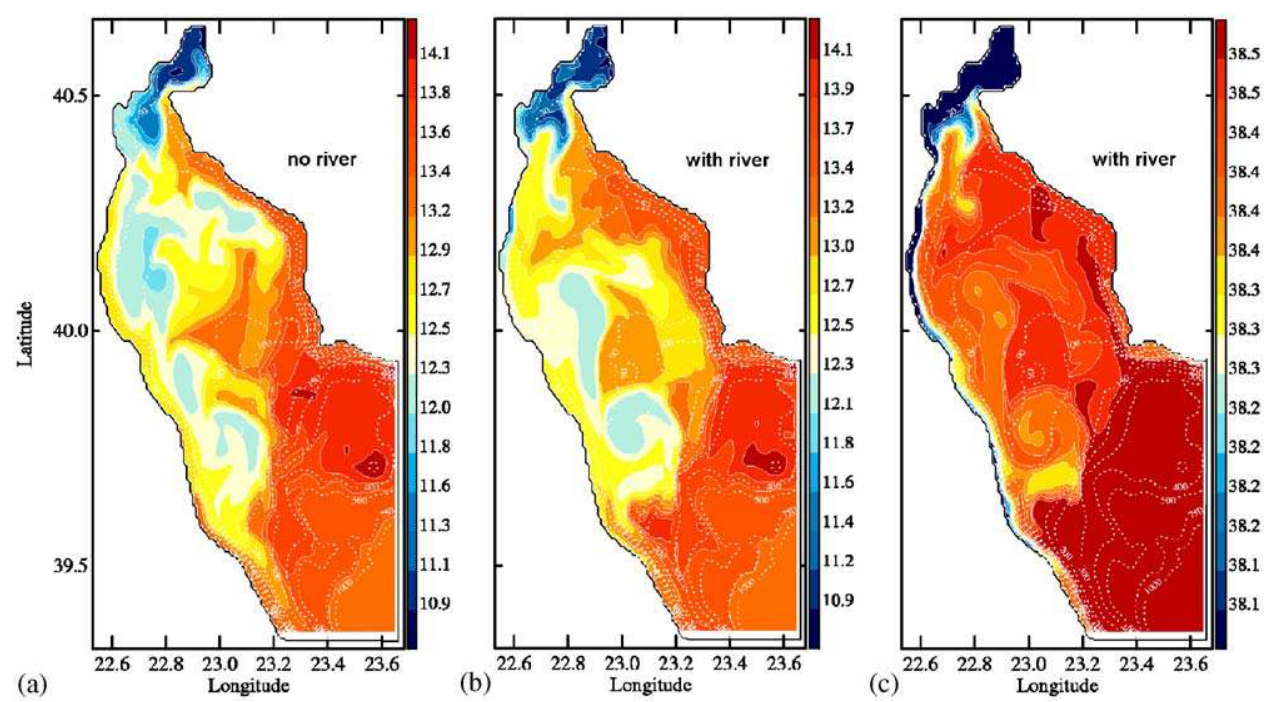

Fig. 8. Bottom temperature or salinity field simulated for 1 February 2002 (day 397): (a) Temperature simulated without river discharge; (b) temperature simulated with river discharge; and (c) salinity simulated with river discharge. Isobaths superimposed as dotted lines.

bottom temperature is in good agreement with the observations. The two simulations, with and without river discharge, provide similar results. However, the simulation without the river discharge reproduces better the amplitude of the large oscillations, especially around the end of the year. The observed minimum of temperature, at day 380 , is not correctly reproduced in time or intensity (although present a few days too early and attenuated in the simulation). The model heats too regularly after day 380 , whilst the observations show strong heating beginning only on day 395 and preceded by a succession of cold and warm events.

The simulated temperature field corresponding to 1 February (day 397) is presented in Figs. 8(a) and (b), for both simulations (without river discharge and with climatological discharge). Firstly, the coldest temperatures are localised in Thessaloniki Bay, which cannot be validated because of the lack of observations in this area. In the domain described by the CTD profiles (Fig. 5), the minima of temperature are quite well localised to the North of the gulf and parallel to the West coast, these regions being separated by relatively warm water. As in the observations, the coastal waters from the East coast are significantly warmer than the cold mid-shelf water. However, this contrast is lower in the simulation $\left(1.2^{\circ} \mathrm{C}\right)$ than in the observed field (about $2.7^{\circ} \mathrm{C}$ ); this is related to the premature heating of bottom waters in the simulation (Fig. 7). The comparison of both simulations shows that the freshwater discharge does not influence strongly the formation of cold water, or its distribution on the shelf (the influence on the cascading in the deep basin will be discussed later). The bottom salinity field, corresponding to the simulation with climatological river discharge (Fig. 8c), shows that, as in the data, low salinities are associated with cold waters; this confirms the coastal origin of these dense water masses. On the shelf, the bottom water temperature difference between the simulations, forced with seasonal minimum river temperatures of $8{ }^{\circ} \mathrm{C}$ and $2{ }^{\circ} \mathrm{C}$ (the latter not shown here), is lower than $1^{\circ} \mathrm{C}$.

Concerning the currents measured at the buoy, it is difficult to make a point to point comparison between the observations and modelling, because of the strong non-stationary character of currents; this is due to wind forcing, at different scales, inertial oscillations, boundary conditions, etc. Therefore, it was decided to validate the trends of the simulated currents, by comparing the progressive vector plots, at $3 \mathrm{~m}$ below the surface and at $5 \mathrm{~m}$ above the bottom deduced from the simulation with the observations (Fig. 9). Concerning the simulation, it was noted that the location of the buoy was an area of transition between two 'veins' of currents. As a consequence, the simulated progressive vector plot is shown at two points: the first one corresponding to the grid point collocated with the buoy, and the second one located $3 \mathrm{~km}$ to the West. The first characteristic is the reversal of both the 

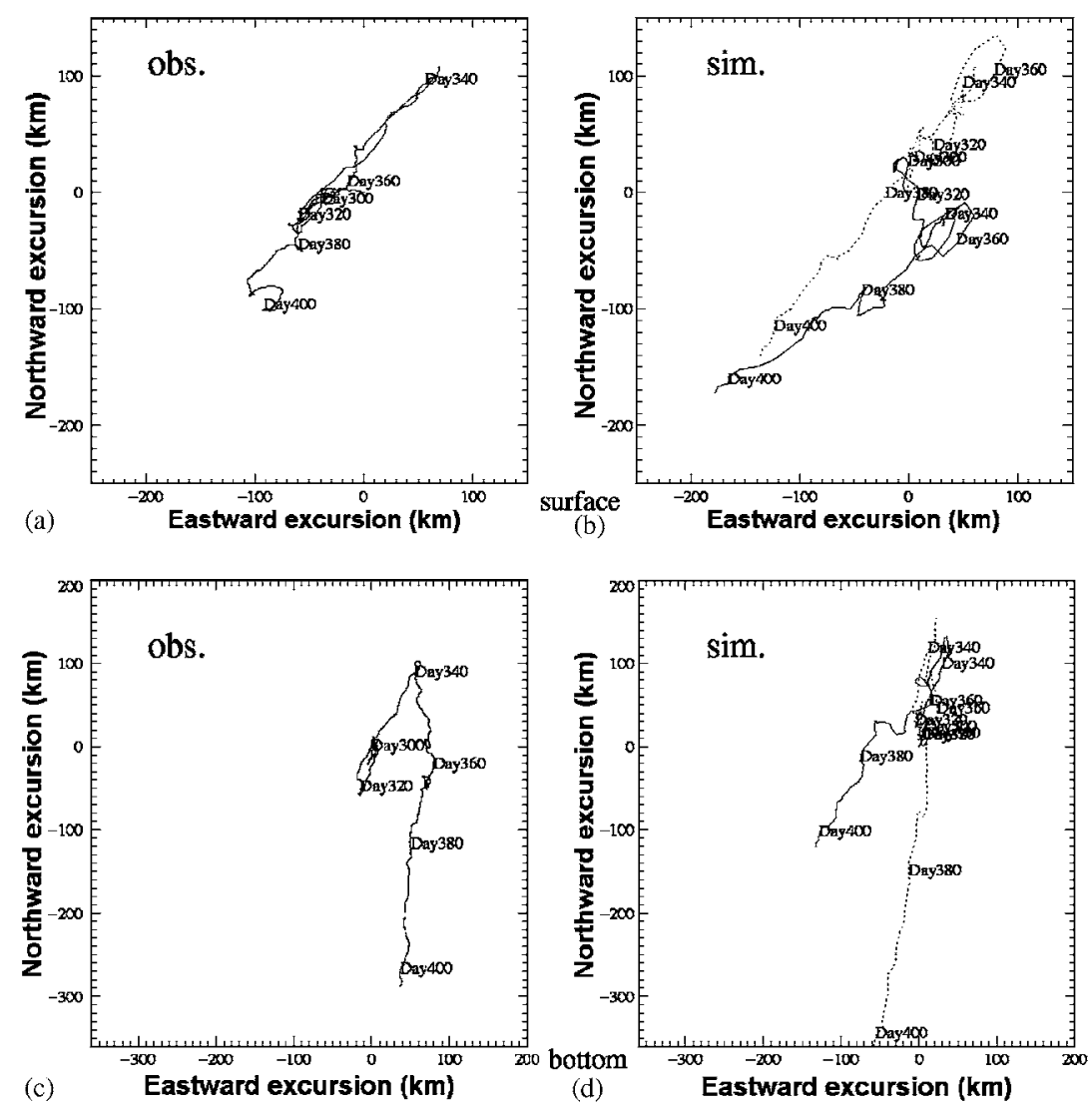

Fig. 9. Progressive vector plots for currents measured at $3 \mathrm{~m}$ below the surface (upper panel) and $5 \mathrm{~m}$ above the bottom (lower panel). (a) and (c) Calculated from the currents measured at the buoy; (b) and (d) calculated from the simulated currents (the two curves correspond to the values at two grid points $3 \mathrm{~km}$ apart).

subsurface and bottom currents, around day 340; this is displayed by the model and is consistent with the observations. The mean current direction and velocity are rather well reproduced by the model, near the surface. Near the bottom, the simulation produces a slightly too large EW component of the current. As the two neighbouring grid points exhibit large differences in velocity, it is difficult to provide an accurate conclusion about this comparison, apart from stating that the model produces bottom currents that are in reasonable agreement with the observations.

To summarise this comparison between the simulation and the observations, the simulation appears to be able to reproduce the cooling of the shelf, caused by the succession of cold wind events. The formation and cascading of dense water is also reproduced. The extent of the area affected by this cascading and/or dispersion is of the same order as that shown by the observations. However, the mechanism does not appear as intense in the simulation as it is in the observations; this is shown by the "too-early" simulated heating at the buoy site, which is confirmed at mesoscale by the "toohigh" temperatures simulated in the area affected by the cascading, during the period of the cruise. These observation/simulation differences will be analysed at the end of Section 6.1. Considering the complexity of the gulf, due to its topography and its forcing, it is difficult to draw conclusions on the quality of the "globally simulated" circulation, with a time series of currents available only at a single point. In Section 6.1, we will use mid-depth currents measured in the northern gulf, during a similar period (winter 1994-1995), to improve our validation and, thus, to allow the interpretation of the results of the simulation in this key region for the formation of dense water.

As the simulation reproduces the main observed steps of the processes of dense water formation and 
cascading, the model is used in the following sections to study the details of the origin and fate of these cold waters: likewise, the physical factors influencing both their formation and their cascading.

\section{Discussion}

The model shows that the densest waters are located within Thessaloniki Bay throughout the simulation, indicating that the dense water formation takes place there, as previously observed by Hyder et al. (2002). Different factors linked to the topography (bathymetry and coastline) are in favour of this location, as outlined below.

- Shallow waters which allow rapid cooling under the action of cold wind; however, this characteristic is shared also by the whole of the coastal band within the gulf. In addition, it was established from the meteorological model that total heat losses are stronger along the western coast than in Thessaloniki Bay; this is due to increasing wind, from North to South.

- Confined situation of the bay, which increases the residence times of waters and thus their exposure to cooling is in contrast with the quasirectilinear western and eastern coasts characterised by strong coastal jets associated with wind forcing. We shall study the role of the wind on the confinement of the bay waters, by examining the currents in the northern gulf, just to the South of Thessaloniki Bay.

\subsection{Circulation in the northern Gulf-consequences of dense water formation and cascading}

Hyder et al. (2002) analysed a time series of middepth $(14 \mathrm{~m})$ currents, at a mooring located in the western part of the northern Gulf (see Section 4.3 above, and the location of this mooring on Fig. 1). These investigators observed a relatively strong persistent northward drift, over 200 days from November to May; this was in 1994-1995 the "winter period", characterised by persistent northerly winds in the gulf. With the objective of validating our simulation, the simulated current at the same point was analysed during our period of similar winds (November 20-January 5). The mean direction of the drift was North-northwest and the mean current was similar to the observed value.
This satisfying comparison allows the model to be used to go further into the analysis of the circulation, in this small region. Although the wind-driven current in the surface layer is southward, the depth-integrated flow at the mooring is northward, as it is at mid-depth. Hyder et al. (2002) suggest that this northward net flux could be compensated by a southward flow in the eastern part of the northern gulf, forming a clockwise gyre. The results of the model confirm this hypothesis, even though a southward current is also found sometimes, in a narrow band along the western coast. We analysed the variability of the bottom current, especially of its direction, together with its impact on the exchanges between the northern gulf and Thessaloniki Bay, through dense water cascading. Fig. 10 shows the variation of the wind and of the South-North component of the bottom current in the northern gulf, together with the mean temperature in Thessaloniki Bay (for clarity, one mean daily value is plotted in the Figure). It is clear that, when the wind is strong, bottom currents like the mid-depth currents tend to be northward (positive values) corresponding to upwelling conditions. Under such conditions, Thessaloniki Bay is almost isolated from the northern Gulf; this results in the mean temperature of the bay decreasing under the effect of the wind and associated heat losses. This characteristic can be observed in Fig. 10. As long as the wind blows (with a limit not reached here, because of the intermittency of wind), the contrast in density between the bottom waters of the bay (progressively densified) and the bottom waters of the northern gulf (less sensitive to the wind, because flowing from the deeper regions of the shelf) increases. This pattern leads to a marked front at the entrance of the bay (Fig. 11a) with a density difference between the two sides reaching $1 \mathrm{~kg} \mathrm{~m}^{-3}$ on day 370 . When the wind decays, the upwelling relaxes and the cascading of dense water takes place, with a southward current (negative on Fig. 10). The mean temperature of the bay increases, as cold bottom water is replaced by relatively warmer surface water flowing from the northern gulf. According to the model, the most intense event occurs around day 370, when the wind is the strongest and the most persistent of the whole period, the upwelling current is strong and the water of the bay reaches its minimum temperature $\left(7^{\circ} \mathrm{C}\right)$. The resulting cascading produced after this event, is at the origin of the minimum of temperature simulated at the "buoy grid point" on day 376 ; it 


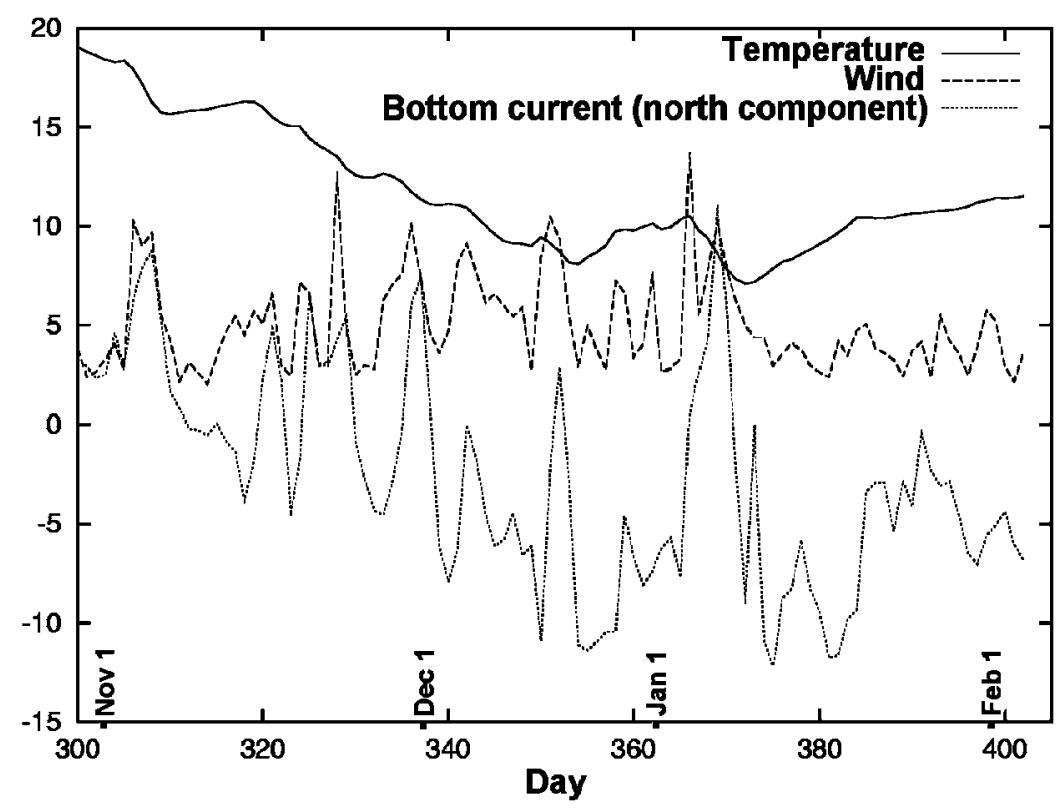

Fig. 10. Time variation of North-South component of the simulated bottom current $\left(\mathrm{cm} \mathrm{s}^{-1}\right)$ in the northern gulf (dotted line); wind $\left(\mathrm{m} \mathrm{s}^{-1}\right)$, obtained from the meteorological model in the northern gulf (dashed line); and mean temperature $\left({ }^{\circ} \mathrm{C}\right)$, as simulated for Thessaloniki Bay (solid line).

probably corresponds also to the coldest observation recorded 3 days later (Fig. 7). In the same way, the relative minima of temperature observed and simulated (especially by the simulation without river discharge) around days 350 and 358 (Fig. 7) can be related to two cascading events (see maximal negative current on Fig. 10), each one following a period of wind activity. Therefore, the wind is the main forcing factor controlling the cascading out of Thessaloniki Bay, with probably a threshold value; this depends upon the density gradient between Thessaloniki Bay and the northern gulf. Consequently, the underestimation of the wind speed by the meteorological model between days 372 and 385 (Fig. 2) could explain at least a part of the differences between the simulation and the observations after day 375 , especially the new cascading event observed around day 390 (Fig. 7), but not reproduced by the simulation. Although less strong and less cold than around day 370, this wind is probably responsible for this new dense water formation in Thessaloniki Bay. Consequently, the sudden decrease of wind on day 385 is probably the event allowing this newly formed water to cascade. The failure of the simulation to reproduce this late January event could be responsible for at least a part of the overestimation of the dense water temperature at the beginning of February, during the cruise (Fig. 8). The underestimation of strong winds as indicated by the negative bias of the wind used to force the model (Table 2) could also be responsible partly for the "too-high" simulated bottom temperatures (it should be noted that the difference between the simulated wind and the observation at the buoy is underestimated in Table 2, due to the difference of altitude between the model $(10 \mathrm{~m})$ and the anemometer $(3.5 \mathrm{~m}))$.

A heat and salt budget of the Thessaloniki Bay was established from the model results, to quantify the role of the different processes. Between days 366 and 372, the mean cooling is of the order of $0.6^{\circ} \mathrm{Cday}^{-1}$. This value is consistent with the heat loss corresponding to the total daily averaged flux (sum of solar and long-wave radiative fluxes, sensible and latent heat fluxes) at the sea surface $\left(\sim 400 \mathrm{~W} \mathrm{~m}^{-2}\right)$, over a water column $15 \mathrm{~m}$ thick.

A crude estimation of the characteristics of the outflow (thickness, width and velocity of the cascading) and of the volume of the bay establishes that about $5-10 \%$ of the water volume of the bay is renewed every day, by the inflow compensating the cascading outflow. After the dense water formation event of days 365-372, the difference of temperature 

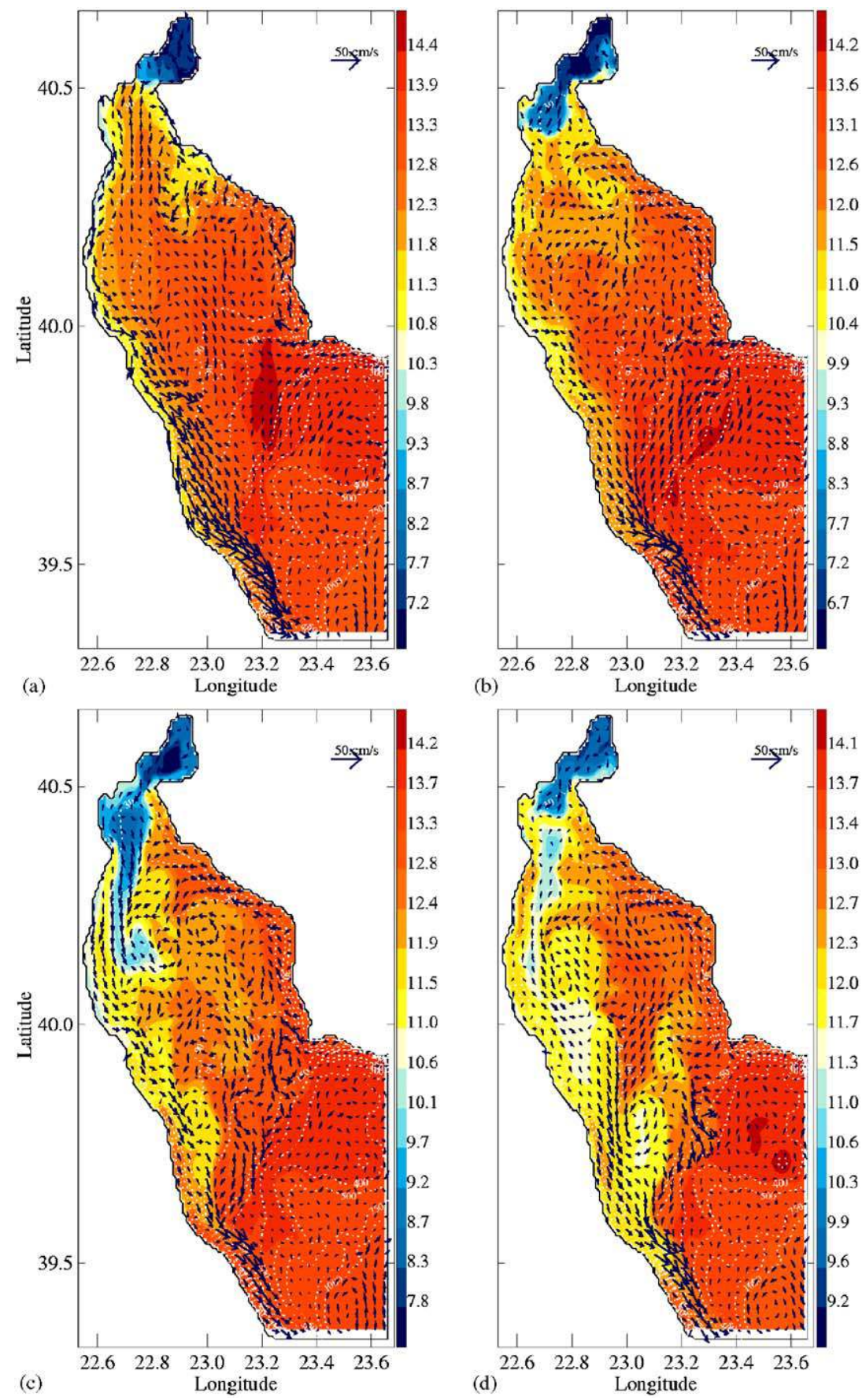

Fig. 11. Simulated near-bottom temperature and current corresponding to (a) 5 January (day 370), (b) 9 January (day 374 ), (c) 13 January (day 378), (d) 23 January (day 388). Isobaths superimposed as dotted lines.

between the outflow and the inflow is about $4{ }^{\circ} \mathrm{C}$. The heating produced by this water exchange is then of the order of $0.3{ }^{\circ} \mathrm{C} \mathrm{day}^{-1}$, which is consistent with the temperature curve of Fig. 10. During strong and cold wind events, the atmospheric fluxes, removing heat from the confined bay waters, are thus responsible for the formation of dense water. When the wind stops, dense water cascades and is replaced by warmer water, until a new wind event produces a new dense water mass. 
The density of the water formed also depends upon evaporation during wind periods and the salinity of the inflow, linked to the river influence during calm periods. During the wind events, the mean salinity of the bay typically increases by 0.02 psu day $^{-1}$, due to evaporation. The effect of rivers appears more irregular, as it depends mainly on the orientation of the Axios plume. During short periods, the intrusion of the plume into the bay strongly decreases its salinity (typically $0.04 \mathrm{psuday}^{-1}$ ). More often, the periods of low wind are characterised by slight increases in the salinity, due to the fact that, as in the case of wide estuaries, the structure of the current at the entrance of Thessaloniki Bay presents a cross-estuary asymmetry (both surface and counter current hugging the bank, located on their right, due to the Coriolis force). In our case, the inflow hugs the East coast of the inner gulf advecting marine waters into the bay, as can be seen in Fig. 8c. Globally, the successive advections of riverine and marine water at the beginning of February produce a mean salinity of the bay of 38 when the river discharge is taken into account, and of 38.5 when it is neglected; this shows that the effect of rivers is far from negligible. The consequences on the cascading in the northern part of the shelf are weak, as the rivers affect also the salinity in this region, resulting in only a limited density contrast between the dense water and its environment. This is not the case in the deep basin not influenced by the rivers where the equilibrium depth of the cascading appears to be affected by the initial salinity of the cold water, as will be discussed at the end of Section 6.2.

\subsection{Characteristics of the cascading}

\subsubsection{Along-slope propagation}

The simulation provides some information about the characteristics of the cascading. We have just seen that sharp reductions in bottom temperature, recorded at the buoy on days $350,358,379$, and produced more or less simultaneously by the simulation, can be linked to a strong bottom southward-cascading current at the entrance of Thessaloniki Bay (about $25 \mathrm{~km}$ to the North), this cascading being allowed by a break in strong northerly wind. The time-lag between the events at these two locations is difficult to estimate accurately, because the variations of the bottom currents are not very distinct, but it is less than 5 days. More accurately, the advance of the front, leading the cold water, was estimated by analysing successive outputs of the model. During the period from day 374 to day 378 (Figs. 11(b) and (c)), where the cascading is the dominant process in the simulation, the front progresses with a velocity of $9-10 \mathrm{~cm} \mathrm{~s}^{-1}$. This velocity can be compared to the Nof speed, which is the theoretical along-slope translation speed of dense lenses, resulting from a balance between downslope reduced-gravity and Coriolis force (Nof, 1983):

$u_{\mathrm{nof}}=\frac{g^{\prime} S}{f}$,

where $g^{\prime}$ is the reduced gravity, $S$ the bottom slope and $f$ the Coriolis parameter.

This speed was estimated along the trajectory of the dense water movement. On the shelf, it decreases from North to South initially, because the slope reduces as the dense water flows toward the centre of the shelf under the effect of bottom friction (see below). Also, because the density of the dense water decreases from North to South, by dispersion. The estimations around day 375 vary between $18 \mathrm{~cm} \mathrm{~s}^{-1}$ in the northern gulf and $5 \mathrm{~cm} \mathrm{~s}^{-1}$ at a latitude of $40^{\circ} \mathrm{N}$, which is consistent with the propagation of the dense water in the simulation. When the dense water reaches the continental slope region, it flows mainly along the isobaths following the western coast (Fig. 8); here the slope is about 30 times as steep as on the shelf. The contrast of density between the dense water and its environment is of the order of $0.08 \mathrm{~kg} \mathrm{~m}^{-3}$, giving a Nof speed around $33 \mathrm{~cm} \mathrm{~s}^{-1}$. The simulation shows along-slope currents of up to $40 \mathrm{~cm} \mathrm{~s}^{-1}$, at $200 \mathrm{~m}$ depth (Figs. 11(b) and (c)).

\subsubsection{Downslope propagation}

Concerning the downslope motion on the shelf, the bottom temperature field obtained from the CTD profiles (Fig. 5) reveals that the trajectory of the dense water has an important down-slope component, confirmed by the simulation. The dense waters are systematically present in a band parallel to the West coast, which comes out as an alongslope channelised flow at the southwestern limit of the gulf (Figs. 8 and 11); however, they develop also complicated shapes on the shelf. The available observations have been completed by the simulation, which shows results in close agreement in areas where they can be compared: the dense water lens in the south of the northern gulf $\left(40.4^{\circ} \mathrm{N}\right)$ is centred on the $35 \mathrm{~m}$ isobath, whilst $30 \mathrm{~km}$ to the South 
$\left(40.1^{\circ} \mathrm{N}\right)$, it crosses the $70 \mathrm{~m}$ isobath and the $100 \mathrm{~m}$ isobath, some $50 \mathrm{~km}$ farther to the South. As already mentioned, when the dense water meets the shelf break of the gulf, the simulation shows that the preferential pathway is parallel to the western coast. The dense layer is very narrow there $(\sim 2-3 \mathrm{~km})$, flowing against the topography at a depth of a few hundred metres in the vicinity of the southwestern corner of the model.

The simulation results show also that the trajectory of the dense water across the shelf cannot be compared to a simple displacement of a circular dense lens, as presented by Shapiro and Hill (2003); this is particularly since the dense water pool appears strongly elongated in the North-South direction, a few days after an intense event of cascading at the entrance of the Thessaloniki Bay (Fig. 11c). This characteristic is due to the narrowness of the strait between the bay and the northern gulf. The dense water is confined within the bay at a depth of 20-25 m, whilst the width of the strait at these depths is about $2-3 \mathrm{~km}$; this would prevent free cascading of the whole water lens. Therefore, the flow is accelerated in the strait; the plume widens again at the exit in the northern gulf, extending as long as the conditions for cascading from the bay are favourable. Farther downstream, different processes, such as the variations of the ambient circulation forced by the wind and the large-scale oceanic circulation, lead to distortion and division of the dense water pools. Nevertheless, if we schematise the behaviour of the cascading on the shelf, using the classification established by Shapiro and Hill (2003) in their study of the effect of friction on dense lens shapes, our simulation gives a propagation configuration that appears to be of the "head-up" type. This is a consequence of a situation in which the lens is initially thick, in comparison with the Ekman depth. The net downslope (eastward) transport, characteristic of the bottom Ekman layer, particularly affects the thin sides of the lens and modifies its cross-slope symmetry. The steepest isopycnals occur on the upslope side (in our case, towards the western coast), whilst the downslope side of the lens (toward the centre of the shelf) is thin.

The thick core of the lens is less sensitive to friction and propagates mainly along-slope (the ideal case for inviscid lenses flowing at the Nof speed), whilst the Ekman drainage generates a tail of fluid behind the lens (Shapiro and Hill, 2003). This process is superimposed upon the stretching, linked to the passage of the strait (as discussed above). This thick core corresponds, in our case, to the dense water which forms a more or less continuous band along the western coast.

On the downslope side of the dense water pool (towards the centre of the shelf), the low bathymetric slope is not favourable to rapid downslope propagation of this part of the lens. Because of the crescent shape of the gulf, the orientation of the slope changes as the downslope side of the lens approaches the middle of the shelf. This means that the downslope side of the dense lens tends to experience a westward Nof speed, opposite to the eastward downslope component of the thick core; this, in turn, enhances the stagnation of the midshelf dense water lenses. As a consequence, thin dense water pools are dispersed on the shelf by the ambient circulation or instabilities, with dense water remaining longer in the coastal zone. This mechanism explains also the complicated contours of the dense water, as shown in Fig. 8. The progression of this dense water, through the shelf break, is slow. When the front bounding the dense pool is sufficiently abrupt, the associated pressure gradient induces cross-slope currents. A part of the lens cascades into the central canyon (Fig. 11d), but the dense layer develops mainly an along-slope current that drives it to the southwest. Finally it rejoins the main branch flowing along the western coast.

The slope bounding the West coast then appears as a preferential pathway for the major part of the dense water formed on the shelf: the main branch flows directly on the upslope side, whilst the water mass flowing on the downslope side, with more "chaotic" pathways on the shelf, finally passes through the shelf break; it is then deviated along the slope, finally meeting the main branch again. The equilibrium depth of the dense water depends upon its density which, in itself, depends upon the discharge of rivers of the northern Gulf (see Section 6.1). The simulation forced with the climatological discharges produces lenses which cascade to 250-300 m (depending upon the freshwater temperature) whilst, without discharge, the maximum depth reached by the lens is about $450 \mathrm{~m}$.

\section{Conclusions}

Dense water is formed in winter, mainly in the Bay of Thessaloniki, as a response to cold northerly winds. This cooling is reinforced by the effect of northward bottom currents, induced by the wind, 
which confine the dense water in the bay. Under such conditions, the exchanges with the shelf are limited to very narrow coastal jets, developing especially along the northeastern coast, as a barotropic response to the alongshore wind (Fig. 11a). When the northerly wind decreases, dense water cascades southward, in a 10-m-thick bottom layer stretching through the northern gulf and then on to the western part of the shelf. The current in the dense water layer is consistent with the theoretical value of the Nof speed, characterising the along-slope propagation of inviscid lenses, of the order of $5-15 \mathrm{~cm} \mathrm{~s}^{-1}$ on the shelf to $30 \mathrm{~cm} \mathrm{~s}^{-1}$ along the steep slope bordering the Sporades Basin, to the South of the gulf. As the dense water progresses southward, a downslope component, induced by bottom friction, breaks the West-East symmetry of the dense water layer. The result on the upslope side (towards the coast) is that the thick core of the lenses hugs the slope and progressively sinks. In our case, dense water is exported out of the gulf, at depths of between 250 and $400 \mathrm{~m}$, depending on the freshwater discharge of rivers located in the vicinity of the region of dense water formation (mainly the Axios river). On the downslope side (towards the centre of the shelf), the progression of the dense water is slow, due to the low values of the slope; it is influenced then by the ambient circulation, or the development of instabilities.

Dense water formation in Thermaikos Gulf appears to be a physical process, able to export continental matter toward the basin. Firstly, the dense water forms in the Thessaloniki Bay, where substantial amounts of inorganic and organic pollutants produced by industrial activity and domestic effluents from the city and port of Thessaloniki (population $>1,000,000$ ) are introduced (Karageorgis and Anagnostou, 2003). Our computations indicate that $5-10 \%$ of the water volume of the bay is exported every day, by cascading. The integrated duration of cascading, during the winter of 2001-2002, was about 50 days; this represents several complete renewals of the bay waters. Secondly, the input of the main river of the gulf (Axios R.), which supplies about 1 million tons of particulate matter per year to the gulf, occurs mainly in winter. A large part of this particulate matter settles in front of the mouth, on the prodelta. It is possible that dense water cascading sweeps away part of this unconsolidated particulate matter, if the turbulence induced by waves and/or currents is able to produce resuspension. The effect of the dense water cascading, as described in this paper, on the exportation of particulate matter from the coastal zone, to the deep basin, still remains to be investigated.

\section{Acknowledgments}

This research was performed in the frame of the INTERPOL project supported by the European Union under contract EVK3-2000-00023. The authors are grateful to A. Karageorgis for providing the bathymetry.

\section{References}

Auclair, F., Casitas, S., Marsaleix, P., 2000. Application of an inverse method to coastal modelling. Journal of Atmospheric and Oceanic Technology 17, 1368-1391.

Beckers, J.M., 1995. La Méditerranée occidentale: de la modélisation mathématique à la simulation numérique. Collect. des publ. de la Fac. des Sci. Appl. No. 136, 342pp., University of Liège, Liège, Belgium.

Bethoux, J.P., Durieu de Madron, X., Nyffeler, F., Taillez, D., 2002. Deep water in the western Mediterranean: peculiar 1999 and 2000 characteristics, shelf formation hypothesis, variability since 1970 and geochemical inferences. Journal of Marine Systems 33-34, 117-131.

Blumberg, A.F., Mellor, G., 1987. A description of a three dimensional coastal circulation model. In: Heaps, N. (Ed.), Three Dimensional Coastal Ocean Model 208pp.

Dufau-Julliand, C., Marsaleix, P., Petrenko, A., Dekeyser, I., 2004. Three-dimensional modeling of the Gulf of Lion's hydrodynamics (northwestern Mediterranean) during January 1999 (MOOGLI3 Experiment) and late winter 1999: western Mediterranean intermediate water's (WIW's) formation and its cascading over the shelf break. Journal of Geophysical Research 109, C11002.

Estournel, C., Kondrachoff, V., Marsaleix, P., Vehil, R., 1997. The plume of the Rhône: numerical simulation and remote sensing. Continental Shelf Research 17, 899-924.

Estournel, C., Durrieu de Madron, X., Marsaleix, P., Auclair, F., Julliand, C., Vehil, R., 2003. Observation and modelisation of the winter coastal oceanic circulation in the Gulf of Lions under wind conditions influenced by the continental orography (FETCH experiment). Journal of Geophysical Research 108 (C3) pp. 7-1-7-18.

Fieux, M., 1974. Formation d'eau dense sur le plateau continental du Golfe de Lion. Colloq. Int. CNRS, Processus de formation des eaux profondes.

Gaspar, P., Gregoris, Y., Lefevre, J.M., 1990. A simple eddy kinetic energy model for simulations of the oceanic vertical mixing: tests at station Papa and long-term upper ocean study site. Journal of Geophysical Research 95, 16179-16193.

Geernaert, G.L., 1990. Bulk parameterizations for the wind stress and heat fluxes. In: Geernaert, Plant (Eds.), Surface Waves and Fluxes, vol. 1. Kluwer Academic Publishers, Dordecht (Hingham, MA), pp. 72-91. 
Hyder, P., Simpson, J.H., Christopoulos, S., Krestenitis, Y., 2002. The seasonal cycles of stratification and circulation in the Thermaikos Gulf region of freshwater influence (ROFI), north-west Aegean. Continental Shelf Research 22, 2573-2597.

Kallos, G., Nickovic, S., Papadopoulos, A., Jovic, D., Kakaliagou, O., Misirlis, N., Boukas, L., Mimikou, N., Sakellaridis, G., Papageorgiou, J., Anadranistakis, E., Manousakis, M., 1997. The regional weather forecasting system SKIRON: an overview. Proceedings of the International Symposium on Regional Weather Prediction on Parallel Computer Environments, Athens, Greece. University of Athens, pp. 109-122.

Karageorgis, A., Anagnostou, C., 2001. Particulate matter spatial-temporal distribution and associated surface sediment properties: Thermaikos Gulf and Sporades Basin, NW Aegean Sea. Continental Shelf Research 21, 2141-2153.

Karageorgis, A., Anagnostou, C., 2003. Seasonal variation in the distribution of suspended particulate matter in the northwest Aegean Sea. Journal of Geophysical Research 108 (C8), 3274.

Kontoyiannis, H., Kourafalou, V.H., Papadopoulos, V., 2003. Seasonal characteristics of the hydrology and circulation in the northwest Aegean Sea (eastern Mediterranean): observations and modeling. Journal of Geophysical Research 108 (C9), 3302.

Lapouyade, A., Durrieu de Madron, X., 2001. Seasonal variability of the advective transport of suspended particulate matter and organic carbon in the Gulf of Lions (NW Mediterranean). Oceanologica Acta 24, 295-312.

Large, W.G., Pond, S., 1982. Sensible and latent heat flux measurements over the ocean. Journal of Physical Oceanography $12,464-482$.

Madec, G., Chartier, M., Delecluse, P., Crépon, M., 1991. A three-dimensional numerical study of deep-water formation in the northwestern Mediterranean. Journal of Physical Oceanography $21,1349-1371$

Manca, B.B., Kovacevic, V., Gacic, M., Viezzoli, D., 2002. Dense water formation in the southern Adriatic Sea and spreading into the Ionian Sea in the period 1997-1999. Journal of Marine Systems 33-34, 133-154.

Medoc Group, 1970. Observation of formation of deep water in the Mediterranean Sea. Nature 227, 1037-1040.
Nof, D., 1983. The translation of isolated cold eddies along a sloping bottom. Deep Sea Research 30, 171-182.

Oey, L.Y., Chen, P., 1992. A model simulation of circulation in the north-east Atlantic shelves and seas. Journal of Geophysical Research 97, 20,087-20,115.

Papadopoulos, A., Kallos, G., Katsafados, P., Nickovic, S., 2002. The Poseidon weather forecasting system: an overview. The Global Atmosphere and Ocean Systems 8, 219-237.

Person, R., 1974. Un exemple de descente des eaux superficielles du plateau continental dans un canyon du Golfe du Lion. Colloq. Int. CNRS, Processus de formation des eaux profondes (215), 175-189.

Pietrzak, J., Jakobson, J.B., Burchard, H., Vested, H.J., Petersen, O., 2002. A three-dimensional hydrostatic model for coastal and ocean modelling using a generalised topography following co-ordinate system. Ocean Modelling 4 (2), 173-205.

Send, U., Font, J., Mertens, C., 1996. Recent observation indicates convection's role in deep water circulation. EOS $77,61-65$.

Shapiro, G.I., Hill, A.E., 2003. The alternative density structures of cold/saltwater pools on a sloping bottom: the role of friction. Journal of Physical Oceanography 33, 390-406.

Soukissian, T.H., Chronis, G.Th., Nittis, K., Diamanti, Ch., 2002. Advancement of operational oceanography in Greece. The case of the Poseidon system. The Global Atmosphere and Ocean System 8 (2-3), 119-134.

Tragou, E., Zervakis, V., Papageorgiou, E., Stavrakakis, S., Likousis, V., 2004. Monitoring the physical forcing of resuspension events in the Thermaikos Gulf-NW Aegean during 2001-2003, submitted for publication in this volume, doi:10.1016/j.csr.2005.08.011.

Vilibic, I., 2003. An analysis of dense water production on the North Adriatic shelf. Estuarine, Coastal and Shelf Science 56, 697-707.

Zervakis, V., Krasakopoulou, E., Assimakopoulou, G., Renieris, P., Ballas, D., Mallios, A., Papageorgiou, E., 2003. In situ calibration of biofouling-prone oceanographic sensors in the framework of the POSEIDON project. In: Dahlin, H. et al. (Ed.), Building the European Capacity in Operational Oceanography: Proceedings of the 3rd International Conference on EuroGOOS 3-6 December, 2002, Athens, Greece. Elsevier Oceanography Series, 69, pp. 373-375. 